\title{
Ionic-liquid-assisted synthesis of metal single-atom catalysts for benzene oxidation to phenol
}

\author{
Qikai Shen ${ }^{1,2}$, Peipei $\mathrm{Li}^{1,2}$, Weiming Chen ${ }^{1,2}$, Hongqiang Jin ${ }^{1,2}$, Jia Yu ${ }^{1,2}$, Lei Zhu ${ }^{1,2}$, Zhucheng Yang ${ }^{1,2}$, \\ Runqing Zhao ${ }^{1,2}$, Lirong Zheng ${ }^{3^{*}}$, Weiguo Song ${ }^{1,2^{*}}$ and Changyan $\mathrm{Cao}^{1,2^{*}}$
}

\begin{abstract}
Ionic liquids (ILs) have the advantages of low cost, eco-friendliness, abundant heteroatoms, excellent solubility, and coordinated ability with metal ions. These features make ILs a suitable precursor for fabricating metal singleatom catalysts (SACs). Herein, we prepared various metal single atoms anchored on ultrathin $\mathrm{N}$-doped nanosheets (denoted as $\mathrm{Cu}_{1} / \mathrm{NC}, \mathrm{Fe}_{1} / \mathrm{NC}, \mathrm{Co}_{1} / \mathrm{NC}, \mathrm{Ni}_{1} / \mathrm{NC}$, and $\mathrm{Pd}_{1} / \mathrm{NC}$ ) by direct pyrolysis using ILs and $\mathrm{g}-\mathrm{C}_{3} \mathrm{~N}_{4}$ nanosheets as templates. Taking benzene oxidation to phenol with $\mathrm{H}_{2} \mathrm{O}_{2}$ as a model reaction to evaluate their catalytic performance and potential applications, $\mathrm{Cu}_{1} / \mathrm{NC}$ calcined at $1000^{\circ} \mathrm{C}$ (denoted as $\mathrm{Cu}_{1} / \mathrm{NC}$ 1000) exhibits the highest activity with a turnover frequency of about $200 \mathrm{~h}^{-1}$ in the first $1 \mathrm{~h}$ at $60^{\circ} \mathrm{C}$, which is better than that of most metal SACs reported in the literature. High benzene conversion of $82 \%$ with high phenol selectivity of $96 \%$ and excellent recyclability were achieved using the $\mathrm{Cu}_{1} / \mathrm{NC}-1000$ catalyst. This study provides an efficient general strategy for fabricating SACs using ILs for catalytic applications.
\end{abstract}

Keywords: single-atom catalysis, copper, benzene oxidation, ionic liquids

\section{INTRODUCTION}

Due to the high atom utilization and particular unsaturated coordination environment, single-atom catalysts (SACs) have recently attracted extensive research interest, and they have shown superior catalytic performance in electro/photo/thermal catalytic reactions [1-6]. Various methods have been developed to fabricate SACs, and they can be roughly categorized as "bottom-up" and "top-down" routes based on the starting precursors [7-8]. Nevertheless, abundant coordination heteroatoms or defects are required to stabilize single metal atoms during the preparation processes [9-11]. Heteroatoms with lone pairs of electrons, particularly, $\mathrm{N}, \mathrm{O}, \mathrm{P}$, and $\mathrm{S}$ have strong coordination ability to anchor metal single atoms and provide SACs with unique electronic structures [12-18].

The advantageous features of ionic liquids (ILs), such as lowcost, eco-friendliness, abundant heteroatoms, excellent solubility, and coordinated ability with metal ions make them suitable precursors for fabricating catalysts [19-23]. Through direct pyrolysis, ILs have been used to prepare porous carbon materials with different structural defects and heteroatom doping for oxidative removal of naproxen [24]. Through the pyrolysis of a cationic polyionic liquid with a cobalt (II) chloride anion, coreshell cobalt nanoparticles encapsulated in graphite carbon were obtained to achieve selective dehydrogenation of primary amines to imines [25]. Besides pyrolysis, ILs could be used for the electrostatic stabilization of SACs in the hydrogenation of acetylene [26]. Furthermore, the nanoconfinement of ILs at single-Ni sites could improve $\mathrm{CO}_{2}$ electrocatalytic reduction [27]. Considering the features of ILs and the aforementioned demonstrations, we anticipate that ILs would be a better precursor for anchoring metal atoms [28] to prepare SACs.

Herein, we designed an efficient pathway to synthesize metal SACs using ILs. ILs and metal ions were first coordinated [29] and then coadsorbed on the surface of $\mathrm{g}-\mathrm{C}_{3} \mathrm{~N}_{4}$ nanosheets in water. After water evaporation, metal SACs were obtained through direct pyrolysis of the powder under an argon atmosphere. Various metal SACs $(\mathrm{Cu}, \mathrm{Fe}, \mathrm{Co}, \mathrm{Ni}, \mathrm{Pd}$, etc.) could be fabricated using this strategy. The prepared SACs were tested for benzene oxidation to phenol with $\mathrm{H}_{2} \mathrm{O}_{2}$, a crucial and useful reaction in industry. The results show that $\mathrm{Cu} S A C$ pyrolyzed at $1000^{\circ} \mathrm{C}$ (denoted as $\mathrm{Cu}_{1} / \mathrm{NC}-1000$ ) exhibits the highest activity with a turnover frequency (TOF) of $200 \mathrm{~h}^{-1}$ in the first $1 \mathrm{~h}$ at $60^{\circ} \mathrm{C}$, which is better than that of most metal SACs reported in the literature. High benzene conversion $(82 \%)$ with high phenol selectivity (96\%) and excellent recyclability is achieved using $\mathrm{Cu}_{1} / \mathrm{NC}-1000$.

\section{EXPERIMENTAL SECTION}

\section{Materials}

All chemicals were used as received without further purification. 1-Vinyl-3-ethylimidazolium bromide (VEIMBr) and 1-vinyl-3ethylimidazolium tetrafluoroborate were obtained from Damas Beta. Copper (II) chloride dihydrate $\left(\mathrm{CuCl}_{2} \cdot 2 \mathrm{H}_{2} \mathrm{O}, 98 \%\right)$ was obtained from Acros Organics. Urea (AR), and iron (III) chloride hexahydrate $\left(\mathrm{FeCl}_{3} \cdot 6 \mathrm{H}_{2} \mathrm{O}, \mathrm{CP}\right)$, nickel (II) chloride hexahydrate $\left(\mathrm{NiCl}_{2} \cdot 6 \mathrm{H}_{2} \mathrm{O}, \mathrm{Ar}\right)$, and cobalt (II) chloride hexahydrate $\left(\mathrm{CoCl}_{2} \cdot 6 \mathrm{H}_{2} \mathrm{O}\right.$, Ar) were provided by Shanghai Chemical Reagents, China. $\mathrm{PdCl}_{2}$ was purchased from Shanghai Tuosi

\footnotetext{
${ }^{1}$ Beijing National Laboratory for Molecular Sciences, Laboratory of Molecular Nanostructures and Nanotechnology, CAS Research/Education Center for Excellence in Molecular Sciences, Institute of Chemistry, Chinese Academy of Sciences, Beijing 100190, China

${ }^{2}$ University of Chinese Academy of Sciences, Beijing 100049, China

${ }^{3}$ Beijing Synchrotron Radiation Facility (BSRF), Institute of High Energy Physics, Chinese Academy of Sciences, Beijing 100049, China

* Corresponding authors (emails: cycao@iccas.ac.cn (Cao C); wsong@iccas.ac.cn (Song W); zhenglr@ihep.ac.cn (Zheng L))
} 
Chemical Co., Lt.

\section{Preparation of $\mathrm{g}-\mathrm{C}_{3} \mathrm{~N}_{4}$ nanosheets}

g- $\mathrm{C}_{3} \mathrm{~N}_{4}$ nanosheets were synthesized following the procedure reported in the literature [30]. An amount of urea was put into the crucible with a cover. Then, it was annealed at $550^{\circ} \mathrm{C}$ for $4 \mathrm{~h}$ in a muffle with a heating rate of $2.3^{\circ} \mathrm{C} \mathrm{min}^{-1}$.

\section{Preparation of $\mathrm{Cu}_{1} / \mathrm{NC}$}

Following a typical procedure, $2 \mathrm{mg}$ of $\mathrm{CuCl}_{2} \cdot 2 \mathrm{H}_{2} \mathrm{O}$ and $660 \mathrm{mg}$ of VEIMBr were dissolved in $10 \mathrm{~mL}$ of $\mathrm{H}_{2} \mathrm{O}$. Then, $400 \mathrm{mg}$ of $\mathrm{g}$ $\mathrm{C}_{3} \mathrm{~N}_{4}$ nanosheet was added to the solution. After stirring for $2 \mathrm{~h}$, the solution was frozen-dried. The obtained powder was annealed at a high temperature for $2 \mathrm{~h}$ under an Ar atmosphere at a heating rate of $3^{\circ} \mathrm{C} \mathrm{min}^{-1}$.

\section{Preparation of $\mathrm{Fe}_{1} / \mathrm{NC}, \mathrm{Co}_{1} / \mathrm{NC}$, and $\mathrm{Ni}_{1} / \mathrm{NC}$}

The synthesis of different catalysts was the same as that of $\mathrm{Cu}$ SAC, except that $2 \mathrm{mg}$ of $\mathrm{CuCl}_{2} \cdot 2 \mathrm{H}_{2} \mathrm{O}$ was replaced by $4.8 \mathrm{mg}$ of $\mathrm{FeCl}_{3} \cdot 6 \mathrm{H}_{2} \mathrm{O}, 4 \mathrm{mg}$ of $\mathrm{CoCl}_{2} \cdot 6 \mathrm{H}_{2} \mathrm{O}$, and $4 \mathrm{mg}$ of $\mathrm{NiCl}_{2} \cdot 6 \mathrm{H}_{2} \mathrm{O}$, respectively, for $\mathrm{Fe}_{1} / \mathrm{NC}, \mathrm{Co}_{1} / \mathrm{NC}$, and $\mathrm{Ni}_{1} / \mathrm{NC}$.

\section{Preparation of $\mathbf{P d}_{1}-\mathrm{NC}$}

The synthesis of Pd SAC was the same as that of $\mathrm{Cu}$ SAC except that $2 \mathrm{mg}$ of $\mathrm{CuCl}_{2} \cdot 2 \mathrm{H}_{2} \mathrm{O}$ was replaced by $1 \mathrm{mg}$ of $\mathrm{PdCl}_{2}$ and $660 \mathrm{mg}$ of VEIMBr was replaced by $660 \mathrm{mg}$ of 1-vinyl-3-ethylimidazolium tetrafluoroborate.

\section{Characterizations}

The morphology and microstructures of the samples were characterized using transmission electron microscopy (TEM) (JEM-2100F, JEOL, Japan) and high-resolution TEM (HR-TEM) (JEM-2100F, JEOL, Japan) working at $200 \mathrm{kV}$ and scanning electron microscopy (SEM) (HITACHI S-4800, Japan) working at $10 \mathrm{kV}$. Elemental mapping was obtained using HR-TEM equipped with an Oxford detector. Powder X-ray diffraction (XRD) patterns were obtained using the Rigaku D/max-2500n diffractometer with $\mathrm{Cu} \mathrm{Ka}$ radiation $(\lambda=1.5418 \AA)$ at $40 \mathrm{kV}$ and $200 \mathrm{~mA}$. X-ray photoelectron spectroscopy (XPS) was performed using a VG Scientific ESCALab220i-XL electron spectrometer with $300-\mathrm{W} \mathrm{Al} \mathrm{ka}$ radiation. Inductively coupled plasma atomic emission spectroscopy (ICP-AES, Shimadzu ICPE-9000) was used to measure the loading content of metals on the catalysts. Aberration-corrected high-angle annular dark-field scanning transmission electron microscopy (AC-HAADF-STEM) images were obtained using JEOL ARM300F (JEOL, Tokyo, Japan) scanning transmission electron microscope operated at $200 \mathrm{kV}$ with a cold-field emission gun and double hexapole Cs correctors (CEOS GmbH, Heidelberg, Germany). The BrunauerEmmett-Teller (BET) surface areas of the samples were determined by measuring the $\mathrm{N}_{2}$ adsorption and desorption isotherms on a Micromeritics ASAP 2460 surface area and porosity analyzer at $77 \mathrm{~K}$. Before the BET measurement, all samples were degassed under dynamic vacuum at $220^{\circ} \mathrm{C}$ for $12 \mathrm{~h}$.

\section{XAS measurements and analysis}

X-ray absorption spectroscopy (XAS) was performed at $1 \mathrm{~W} 1 \mathrm{~B}$ station in Beijing Synchrotron Radiation Facility (BSRF). The storage rings of BSRF were operated at $2.5 \mathrm{GeV}$ with an average current of $250 \mathrm{~mA}$. Using Si (111) double-crystal monochromator, data collection was performed in transmission/ fluorescence mode using an ionization chamber. All spectra were collected in ambient conditions.

The acquired extended X-ray absorption fine structure (EXAFS) data were processed according to standard procedures using an ATHENA module implemented in IFEFFIT software. The $k^{3}$-weighted EXAFS spectra were obtained by subtracting the post-edge background from the overall absorption and then normalizing it with respect to the edge-jump step. Subsequently, the $k^{3}$-weighted $\chi(k)$ data of $\mathrm{Cu} \mathrm{K}$-edge were Fourier transformed into real $(\mathrm{R})$ space using a hanning window $(\mathrm{d} k=$ $1.0 \AA^{-1}$ ) to separate the EXAFS contributions from various coordination shells. To obtain the quantitative structural parameters around central atoms, least-squares curve parameter fitting was performed using the ARTEMIS module of IFEFFIT software [31-33].

\section{General catalytic test}

For the catalytic test, $10 \mathrm{mg}$ of catalyst and $6 \mathrm{~mL}$ of methyl cyanide $(\mathrm{MeCN})$ were added to a $25-\mathrm{mL}$ glass reaction tube sealed with a Teflon lid (Beijing Synthware Glass, Inc. Pressure Vessel, HeavyWall). Then, $300 \mu \mathrm{L}$ of benzene and $5 \mathrm{~mL}$ of $\mathrm{H}_{2} \mathrm{O}_{2}$ were added sequentially. The reaction mixture was stirred in a preheated $60^{\circ} \mathrm{C}$ oil bath for a desired time. After the reaction, the reaction mixture was cooled to room temperature and $100 \mu \mathrm{L}$ of $n$-tridecane was added. The solution was extracted using $10 \mathrm{~mL}$ of ethyl acetate, and the solid catalyst was recovered by centrifugation. Then, the catalyst was filtered off, and a sample of the mixture was directly subjected to gas chromatography (GC) or gas chromatography-mass (GC-MS) spectrometry. The gas chromatograph (Shimadzu GC-2010) was equipped with a flame ionization detector and an Rtx-5 capillary column $(0.25 \mathrm{~mm}$ in diameter, $30 \mathrm{~m}$ in length). The GC-MS (Shimadzu GCMSQP2010S) was equipped with an HP-5MS capillary column $(0.25 \mathrm{~mm}$ in diameter, $30 \mathrm{~m}$ in length).

For the time-dependent catalytic performance test, the reaction mixture included $10 \mathrm{mg}$ of catalyst, $6 \mathrm{~mL}$ of $\mathrm{MeCN}, 300 \mu \mathrm{L}$ of benzene, and $5 \mathrm{~mL}$ of $\mathrm{H}_{2} \mathrm{O}_{2}$ at $60^{\circ} \mathrm{C}$. When the reaction time reached $6 \mathrm{~h}$, another $5 \mathrm{~mL}$ of $\mathrm{H}_{2} \mathrm{O}_{2}$ was added.

For the recyclability test, the reaction conditions were: $10 \mathrm{mg}$ of catalyst, $6 \mathrm{~mL}$ of $\mathrm{MeCN}, 300 \mu \mathrm{L}$ of benzene, $5 \mathrm{~mL}$ of $\mathrm{H}_{2} \mathrm{O}_{2}$, $60^{\circ} \mathrm{C}$, and $6 \mathrm{~h}$. At the end of the catalytic reaction, the mixture was centrifuged and the solid was recovered, washed five times with $\mathrm{MeCN}$, dried at $60^{\circ} \mathrm{C}$ under vacuum and then reused in the next run.

\section{RESULTS AND DISCUSSION}

\section{Preparation and characterizations}

Taking $\mathrm{Cu}$ as an example, Scheme 1 illustrates the synthesis procedure for $\mathrm{Cu}_{1} / \mathrm{NC}$ using ILs. SEM and XRD results suggest that the metal cations-ILs complex is uniformly adsorbed on the surface of $\mathrm{g}-\mathrm{C}_{3} \mathrm{~N}_{4}$ nanosheets (Fig. S1). After calcination, the $\mathrm{Cu}$ SACs were denoted as $\mathrm{Cu}_{1} / \mathrm{NC}-800, \mathrm{Cu}_{1} / \mathrm{NC}-900$, and $\mathrm{Cu}_{1} / \mathrm{NC}$ 1000 , corresponding to the calcination temperature of 800,900 and $1000^{\circ} \mathrm{C}$, respectively. The morphology and microstructure of $\mathrm{Cu}_{1} / \mathrm{NC}-1000$ were first characterized by TEM and HR-TEM. As shown in Fig. $1 \mathrm{a}, \mathrm{b}, \mathrm{Cu}_{1} / \mathrm{NC}-1000$ exhibits an ultrathin nanosheet structure, and no nanoparticles could be observed. However, the energy-dispersive X-ray spectroscopy (EDS) mapping images reveal $\mathrm{Cu}$ species dispersed in the nitrogendoped carbon nanosheets (Fig. 1c). The $\mathrm{Cu}$ amount was about 


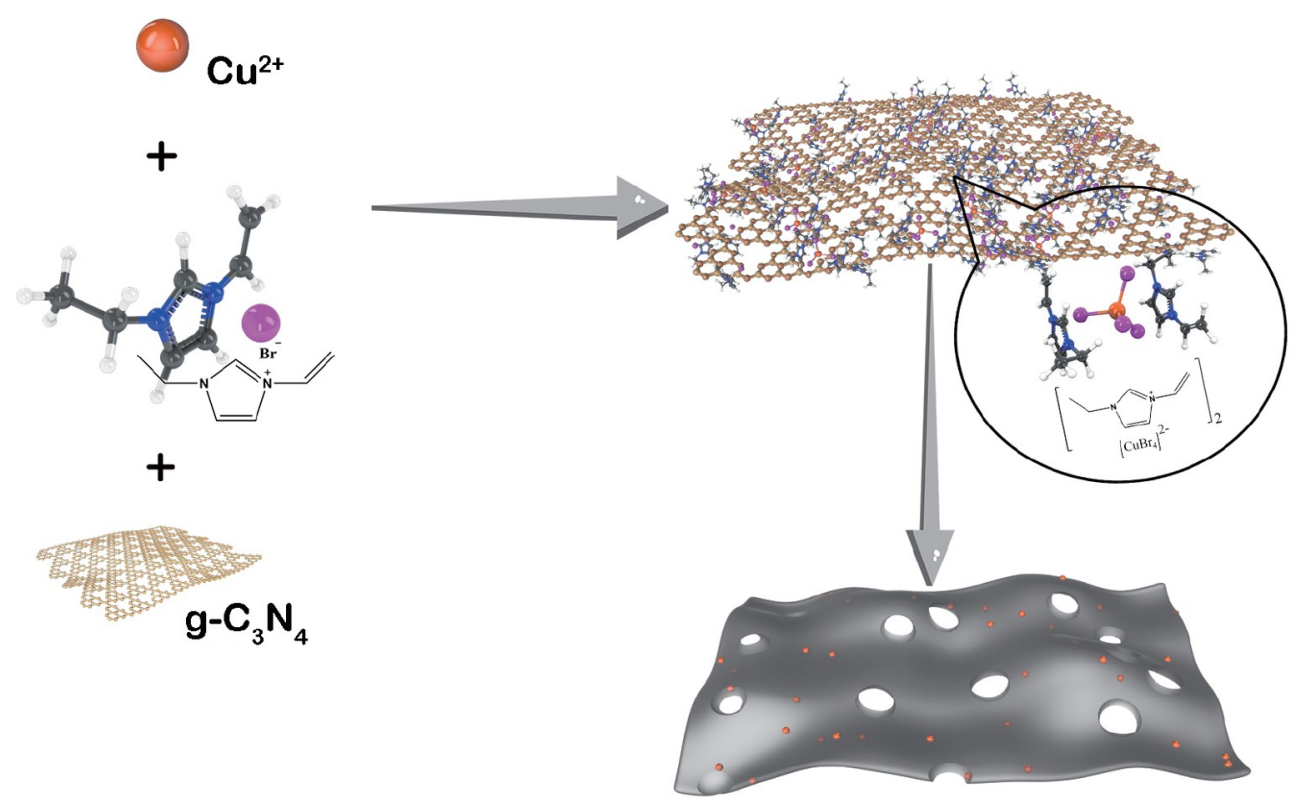

Scheme 1 Schematic illustration of the synthesis of $\mathrm{Cu}_{1} / \mathrm{NC}$ catalyst.
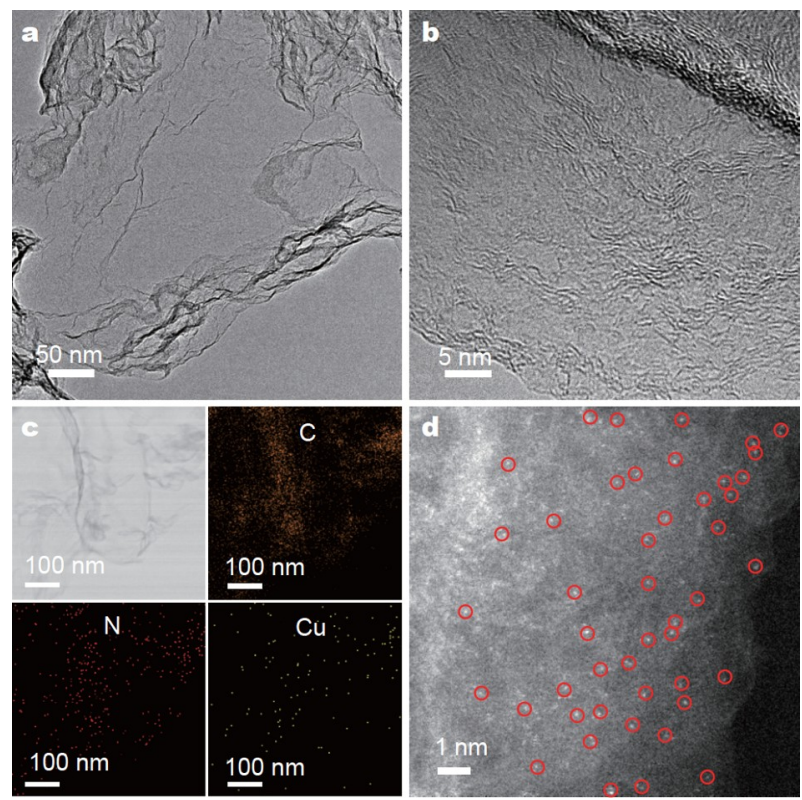

Figure 1 (a) TEM, (b) HR-TEM, (c) EDS mapping, and (d) AC HAADFSTEM images of $\mathrm{Cu}_{1} / \mathrm{NC}-1000$.

$0.9 \mathrm{wt} \%$ according to ICP-AES measurements (Table S1). Further, only two broad peaks at $2 \theta=24^{\circ}$ and $44^{\circ}$, corresponding to graphic carbon, could be observed in the XRD pattern (Fig. S2). These results suggest that $\mathrm{Cu}$ species were highly dispersed on the support. AC HAADF-STEM was further employed. As shown in Fig. 1d, isolated bright dots (highlighted by red circles), which correspond to $\mathrm{Cu}$ single atoms, were observed due to the different $\mathrm{Z}$-contrasts with carbon.

Synchrotron radiation XAFS measurements were then performed to analyze the states and coordination structures of $\mathrm{Cu}$ atoms in $\mathrm{Cu}_{1} / \mathrm{NC}$. The $\mathrm{Cu}$ K-edge X-ray absorption near-edge structure (XANES) curves (Fig. 2a) demonstrate that $\mathrm{Cu}$ species in all $\mathrm{Cu}_{1} / \mathrm{NC}$ samples is between $+1\left(\mathrm{Cu}_{2} \mathrm{O}\right)$ and $+2(\mathrm{CuO})$, suggesting the partial positive charge of $\mathrm{Cu}$. Moreover, there is a shift toward lower energy from $\mathrm{Cu}_{1} / \mathrm{NC}-800$ to $\mathrm{Cu}_{1} / \mathrm{NC}-1000$, indicating a decrease in the oxidation state of $\mathrm{Cu}$ with an increase in the calcination temperature. The XPS spectra confirm the changes in the $\mathrm{Cu}$ species. As shown in Fig. 2d, the peak at $\sim 935 \mathrm{eV}$, corresponding to $\mathrm{Cu}^{2+}$, decreases gradually, and that at $\sim 932 \mathrm{eV}$, corresponding to $\mathrm{Cu}^{+}$, increases gradually [34]. Additionally, from $\mathrm{Cu}_{1} / \mathrm{NC}-800$ to $\mathrm{Cu}_{1} / \mathrm{NC}-1000$, the $\mathrm{N}$ content decreases gradually (Table S2). Fourier-transform $k^{3}$-weighted EXAFS spectra show only one main peak at $\sim 1.5 \AA$ (without a phase change), which is attributed to the $\mathrm{Cu}-\mathrm{N} / \mathrm{C}$ scattering path, and no peak at $2.2 \AA$ of $\mathrm{Cu}-\mathrm{Cu}$ bonds is observed, verifying the sole presence of atomically dispersed $\mathrm{Cu}$ atoms in all $\mathrm{Cu}_{1} / \mathrm{NC}$ samples (Fig. 2b) [35]. Further EXAFS-fitting result shows the average coordination number for $\mathrm{Cu}_{1} / \mathrm{NC}-1000$ is 3.1 , suggesting that a single $\mathrm{Cu}$ atom is mainly coordinated with three nitrogen/ carbon atoms in a carbon matrix (Fig. 2c). However, the average coordination numbers for $\mathrm{Cu}_{1} / \mathrm{NC}-900$ and $\mathrm{Cu}_{1} / \mathrm{NC}-800$ increase to 3.3 and 3.5, respectively (Fig. S3 and Table S3). The coordination structure has a significant influence on catalytic performance [36-37], which is discussed in a later section.

Besides the crucial role of ILs, g- $\mathrm{C}_{3} \mathrm{~N}_{4}$ nanosheets play important roles in the formation of final $\mathrm{Cu}_{1} / \mathrm{NC}$ [38]. First, g$\mathrm{C}_{3} \mathrm{~N}_{4}$ nanosheets are the structural template for ILs layer adsorption and dispersion, which is subsequently calcined to form the nanosheet structure. Second, the complete decomposition of g- $\mathrm{C}_{3} \mathrm{~N}_{4}$ nanosheets releases gases (Fig. S4), which generates additional mesoporosity and improves the surface area of $\mathrm{Cu}_{1} / \mathrm{NC}$ SACs. The $\mathrm{N}_{2}$ adsorption-desorption isotherms of the three $\mathrm{Cu}_{1} / \mathrm{NC}$ catalysts (Fig. S5) show typical type IV curves with $\mathrm{H}_{3}$ hysteresis loops and have a similar BET surface area and pore-size distribution, confirming a mesoporous structure. Thus, the pore structure does not account for the difference in the catalytic activity of the three catalysts. The relatively high specific surface and mesoporous structure improve the mass transfer of the substrate and the activity of the catalysts [39]. Third, few N 

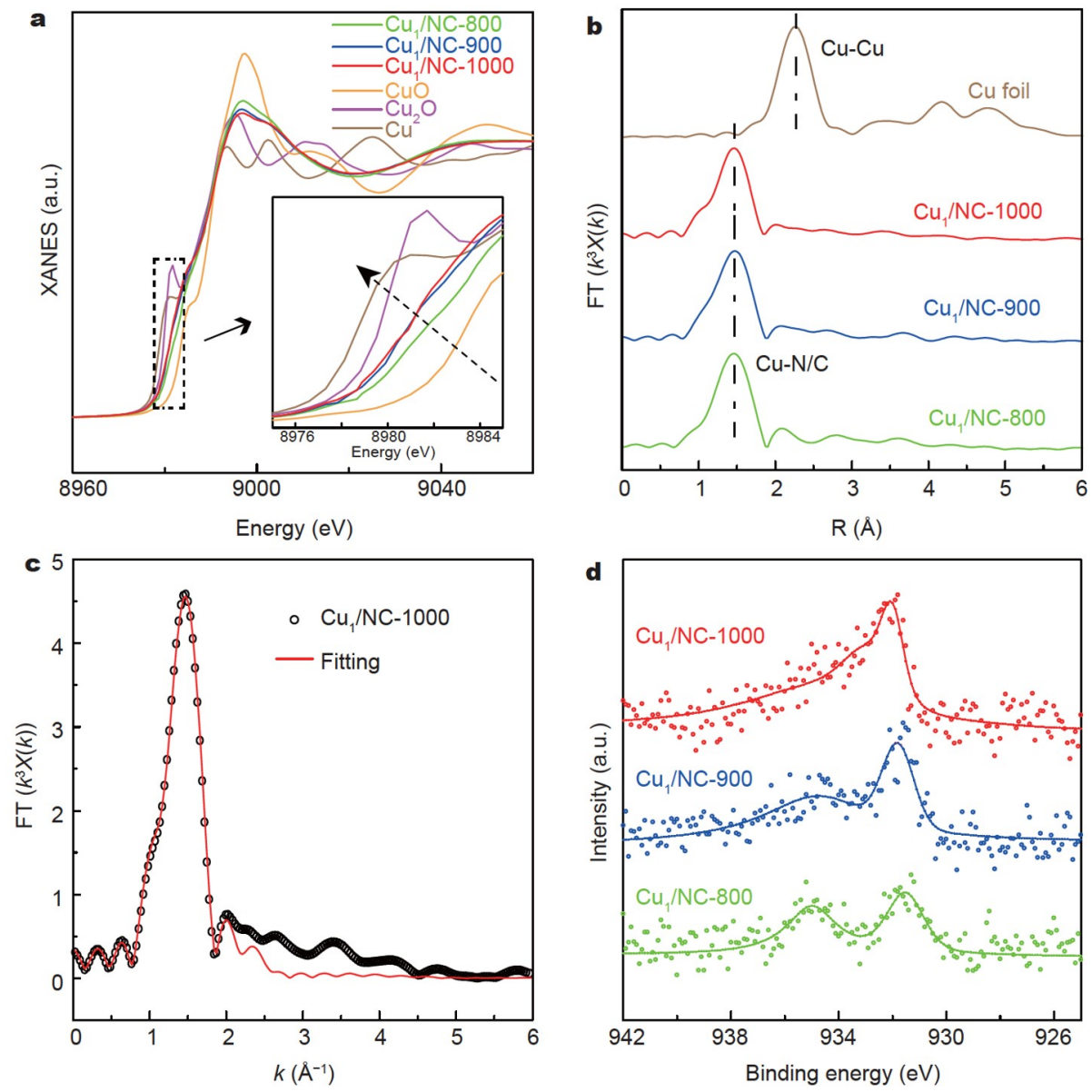

Figure 2 (a) $\mathrm{Cu}$ K-edge XANES spectra of $\mathrm{Cu}_{1} / \mathrm{NC}$ and standard samples. (b) Fourier-transform (FT) EXAFS (FT-EXAFS) spectrum ( $k^{3}$-weighted) of Cu 1 NC-1000 and standard samples in the R space. (c) Corresponding EXAFS fitting curve of $\mathrm{Cu}_{1} / \mathrm{NC}-1000$. (d) Comparison of high-resolution Cu 2p XPS spectra of the obtained catalysts with different calcination temperatures.

atoms in the g- $\mathrm{C}_{3} \mathrm{~N}_{4}$ nanosheets were also doped into the carbon skeleton during pyrolysis, which helps anchor $\mathrm{Cu}$ single atoms. In comparison, the obtained carbon material without $\mathrm{g}-\mathrm{C}_{3} \mathrm{~N}_{4}$ nanosheets was lumpy and the $\mathrm{N}$ content was very low (Fig. S6).

By exploiting the strong coordination ability of ILs and the particular roles of g- $\mathrm{C}_{3} \mathrm{~N}_{4}$ nanosheets, other metal SACs $\left(\mathrm{Fe}_{1} /\right.$ $\mathrm{NC}, \mathrm{Co}_{1} / \mathrm{NC}, \mathrm{Ni}_{1} / \mathrm{NC}$, and $\mathrm{Pd}_{1} / \mathrm{NC}$ ) could also be obtained through the same method. As shown in Fig. S7, all the samples exhibit similar ultrathin nanosheet structures, and no nanoparticles were observed in their TEM images and XRD patterns (Fig. S2). EDS mapping results show that metal species were highly dispersed. The isolated bright dots corresponding to $\mathrm{Fe}$, $\mathrm{Co}, \mathrm{Ni}$, and Pd single atoms were observed in their AC HAADFSTEM images (Fig. 3). These results indicate that this strategy is universal for fabricating metal SACs.

\section{Benzene oxidation reaction performance}

Phenol is one of the important industrial chemicals due to its broad applications in phenolic resin, pharmaceuticals, agrochemicals, etc. [40]. Compared with the traditional three-step cumene process, one-step direct catalytic oxidation of benzene to phenol with $\mathrm{H}_{2} \mathrm{O}_{2}$ over heterogeneous catalysts has the advantages of high efficiency, low cost, and environmental friendliness [41]. Owing to the maximized utility of metal atoms
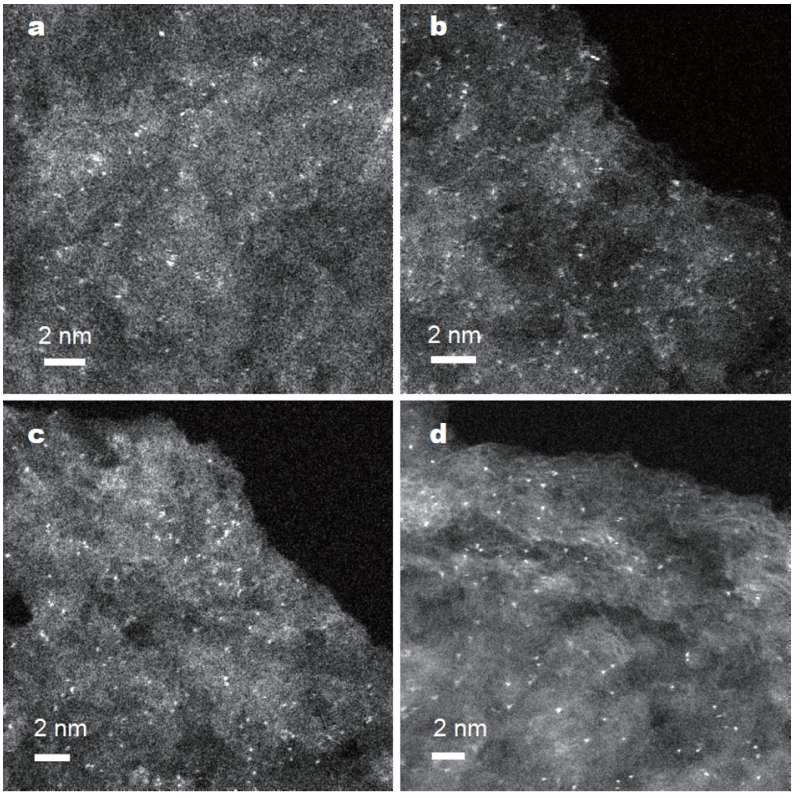

Figure 3 AC HAADF-STEM images of (a) $\mathrm{Fe}_{1} / \mathrm{NC}$, (b) $\mathrm{Co}_{1} / \mathrm{NC}$, (c) $\mathrm{Ni}_{1} /$ $\mathrm{NC}$, and (d) $\mathrm{Pd}_{1} / \mathrm{NC}$. 

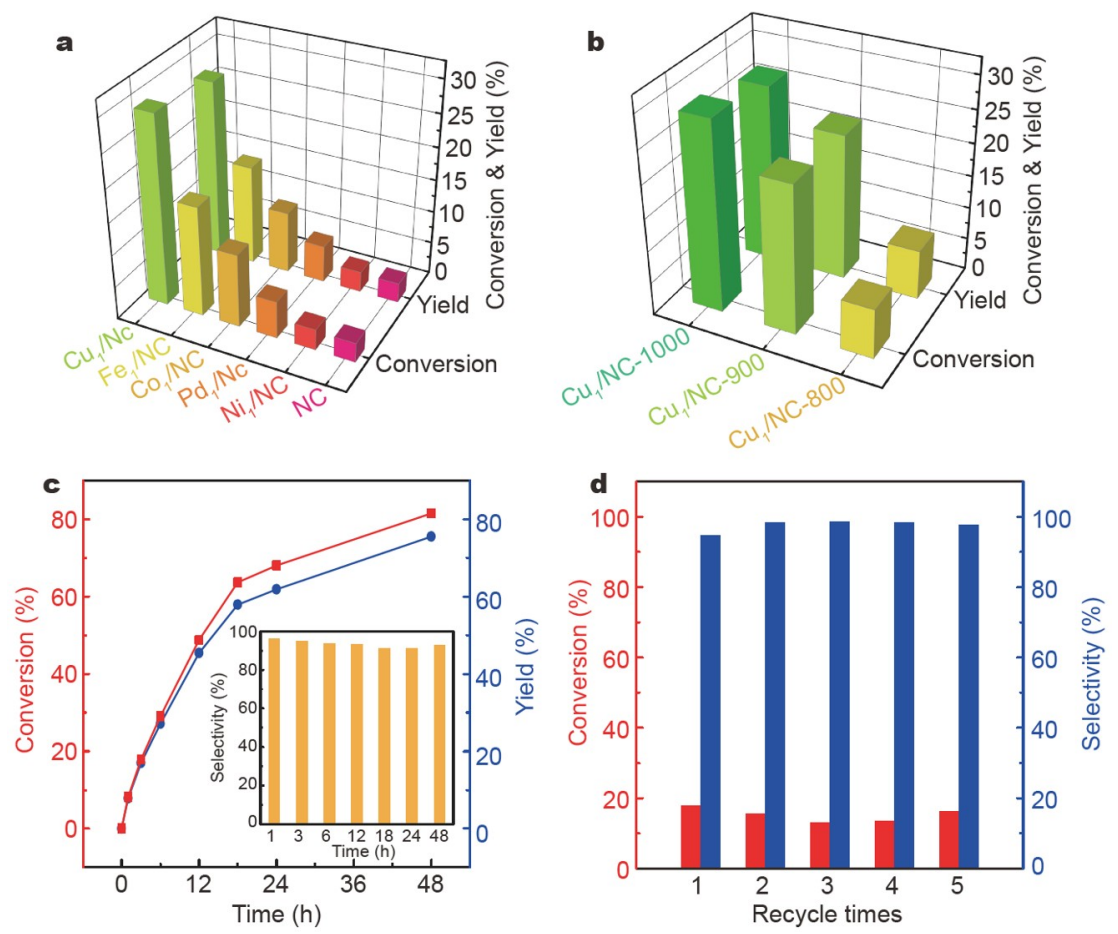

Figure 4 Comparison of benzene oxidation performance of the obtained catalysts with (a) different metal SACs and (b) $\mathrm{Cu} / \mathrm{NC}$ at $60^{\circ} \mathrm{C}$ for $6 \mathrm{~h}$. (c) Timedependent catalytic performance and (d) recycle performance of $\mathrm{Cu}_{1}-\mathrm{NC}-1000$ for benzene oxidation.

and unique coordination structure, several metal SACs have been reported to show much better catalytic performance than the corresponding nanoparticles for this reaction [35,37,41-45].

Thus, benzene oxidation to phenol with $\mathrm{H}_{2} \mathrm{O}_{2}$ was chosen as a model reaction to evaluate the catalytic performance of the asprepared metal SACs [46]. As shown in Fig. 4a, $\mathrm{Cu}_{1} / \mathrm{NC}-1000$ exhibits the highest conversion and yield among the metal SACs under the same conditions at $60^{\circ} \mathrm{C}$ for $6 \mathrm{~h}$. Additionally, $\mathrm{Cu}_{1} /$ $\mathrm{NC}-1000$ shows the best catalytic performance among $\mathrm{Cu}_{1} / \mathrm{NC}$ samples (Fig. 4b), suggesting that coordination structures affect the catalytic activity. The formation of active oxygen species through $\mathrm{H}_{2} \mathrm{O}_{2}$ decomposition plays an important role in benzene oxidation reaction. Thus, electron paramagnetic resonance measurements were conducted. As shown in Fig. S8, OOH* was detected in all tested solutions [44]. Comparing the free radical concentrations, we conclude that $\mathrm{Cu}_{1} / \mathrm{NC}-1000$ with a lower coordination number and valence state of $\mathrm{Cu}$ is more beneficial for $\mathrm{OOH}^{*}$ formation, which reacts with benzene to form phenol. This is consistent with the reports in the literature [43-44,4647].

To further investigate the catalytic performance of $\mathrm{Cu}_{1} / \mathrm{NC}$ 1000, kinetic and cyclic tests were conducted. As shown in Fig. $4 \mathrm{c}$, the reaction rate was maintained at a high level during the first $6 \mathrm{~h}$, after which it gradually decreased due to the continuous consumption of $\mathrm{H}_{2} \mathrm{O}_{2}$. After adding another $5 \mathrm{~mL}$ of $\mathrm{H}_{2} \mathrm{O}_{2}$, the conversion of benzene reached $82 \%$ with phenol selectivity of $96 \%$ at $60^{\circ} \mathrm{C}$. The calculated TOF at the first $1 \mathrm{~h}$ was about $200 \mathrm{~h}^{-1}$, better than that of most catalysts reported in the literature (Table S4) [35,37,40-48]. In addition, there was no obvious decrease in benzene conversion and phenol selectivity after five cycles (Fig. 4d). $\mathrm{Cu}$ species after reuse maintained single atoms, as confirmed by AC HAADF-STEM (Fig. S9) and XAFS analyses (Fig. S10 and Table S3). Only the minor valence state of $\mathrm{Cu}$ was increased after use.

\section{CONCLUSIONS}

We developed an efficient and general strategy to produce various metal SACs $\left(\mathrm{Fe}_{1} / \mathrm{NC}, \mathrm{Co}_{1} / \mathrm{NC}, \mathrm{Ni}_{1} / \mathrm{NC}, \mathrm{Cu}_{1} / \mathrm{NC}\right.$, and $\mathrm{Pd}_{1} /$ $\mathrm{NC}$ ) using ILs. ILs serve as the complexing agent and carbon source to disperse metal ions on the surface of $g-C_{3} N_{4}$ nanosheets. After pyrolysis in argon, metal single atoms anchored on the ultrathin $\mathrm{N}$-doped nanosheets were obtained. Furthermore, the as-prepared $\mathrm{Cu}_{1} / \mathrm{NC}-1000$ exhibited excellent catalytic activity, selectivity, and stability in benzene oxidation to phenol using $\mathrm{H}_{2} \mathrm{O}_{2}$ at $60^{\circ} \mathrm{C}$. This study provides an efficient general strategy for fabricating SACs using ILs for catalytic applications.

Received 29 March 2021; accepted 9 June 2021; published online 30 July 2021

1 Fei H, Dong J, Chen D, et al. Single atom electrocatalysts supported on graphene or graphene-like carbons. Chem Soc Rev, 2019, 48: 52075241

2 Qiao B, Wang A, Yang X, et al. Single-atom catalysis of CO oxidation using $\mathrm{Pt}_{1} / \mathrm{FeO}_{x}$. Nat Chem, 2011, 3: 634-641

3 Kaiser SK, Chen Z, Faust Akl D, et al. Single-atom catalysts across the periodic table. Chem Rev, 2020, 120: 11703-11809

4 Li Z, Ji S, Liu Y, et al. Well-defined materials for heterogeneous catalysis: From nanoparticles to isolated single-atom sites. Chem Rev, 2020, 120: 623-682

5 Gawande MB, Fornasiero P, Zbořil R. Carbon-based single-atom catalysts for advanced applications. ACS Catal, 2020, 10: 2231-2259

6 Zhang L, Zhou M, Wang A, et al. Selective hydrogenation over supported metal catalysts: From nanoparticles to single atoms. Chem Rev, 2020, 120: 683-733

7 Ji S, Chen Y, Wang X, et al. Chemical synthesis of single atomic site catalysts. Chem Rev, 2020, 120: 11900-11955 
8 Rong H, Ji S, Zhang J, et al. Synthetic strategies of supported atomic clusters for heterogeneous catalysis. Nat Commun, 2020, 11: 5884

9 Wan C, Duan X, Huang Y. Molecular design of single-atom catalysts for oxygen reduction reaction. Adv Energy Mater, 2020, 10: 1903815

10 Qin R, Liu K, Wu Q, et al. Surface coordination chemistry of atomically dispersed metal catalysts. Chem Rev, 2020, 120: 11810-11899

11 Peng L, Shang L, Zhang T, et al. Recent advances in the development of single-atom catalysts for oxygen electrocatalysis and zinc-air batteries. Adv Energy Mater, 2020, 10: 2003018

12 Li Q, Chen W, Xiao H, et al. Fe isolated single atoms on S, N codoped carbon by copolymer pyrolysis strategy for highly efficient oxygen reduction reaction. Adv Mater, 2018, 30: 1800588

13 Zhuo HY, Zhang X, Liang JX, et al. Theoretical understandings of graphene-based metal single-atom catalysts: Stability and catalytic performance. Chem Rev, 2020, 120: 12315-12341

14 Yang J, Li W, Wang D, et al. Electronic metal-support interaction of single-atom catalysts and applications in electrocatalysis. Adv Mater, 2020, 32: 2003300

15 Wang L, Chen MX, Yan QQ, et al. A sulfur-tethering synthesis strategy toward high-loading atomically dispersed noble metal catalysts. Sci Adv, 2019, 5: eaax6322

16 Zhao L, Zhang Y, Huang LB, et al. Cascade anchoring strategy for general mass production of high-loading single-atomic metal-nitrogen catalysts. Nat Commun, 2019, 10: 1278

17 Long X, Li Z, Gao G, et al. Graphitic phosphorus coordinated single Fe atoms for hydrogenative transformations. Nat Commun, 2020, 11: 4074

18 Shen Q, Cao C, Huang R, et al. Single chromium atoms supported on titanium dioxide nanoparticles for synergic catalytic methane conversion under mild conditions. Angew Chem Int Ed, 2020, 59: 1216-1219

19 Welton T. Room-temperature ionic liquids. Solvents for synthesis and catalysis. Chem Rev, 1999, 99: 2071-2084

20 Wasserscheid P, Keim W. Ionic liquids-new "solutions" for transition metal catalysis. Angew Chem Int Ed, 2000, 39: 3772-3789

21 Zhao D, Fei Z, Scopelliti R, et al. Synthesis and characterization of ionic liquids incorporating the nitrile functionality. Inorg Chem, 2004, 43: 2197-2205

22 Lin IJB, Vasam CS. Metal-containing ionic liquids and ionic liquid crystals based on imidazolium moiety. J Organomet Chem, 2005, 690: 3498-3512

23 Gong J, Antonietti M, Yuan J. Poly(ionic liquid)-derived carbon with site-specific $\mathrm{N}$-doping and biphasic heterojunction for enhanced $\mathrm{CO}_{2}$ capture and sensing. Angew Chem Int Ed, 2017, 56: 7557-7563

24 Wang J, Duan X, Gao J, et al. Roles of structure defect, oxygen groups and heteroatom doping on carbon in nonradical oxidation of water contaminants. Water Res, 2020, 185: 116244

25 Cui X, Li W, Junge K, et al. Selective acceptorless dehydrogenation of primary amines to imines by core-shell cobalt nanoparticles. Angew Chem Int Ed, 2020, 59: 7501-7507

26 Ding S, Guo Y, Hülsey MJ, et al. Electrostatic stabilization of singleatom catalysts by ionic liquids. Chem, 2019, 5: 3207-3219

27 Ren W, Tan X, Chen X, et al. Confinement of ionic liquids at single-Nisites boost electroreduction of $\mathrm{CO}_{2}$ in aqueous electrolytes. ACS Catal, 2020, 10: 13171-13178

$28 \mathrm{Xu} \mathrm{T}$, Waehler T, Vecchietti J, et al. Gluing ionic liquids to oxide surfaces: Chemical anchoring of functionalized ionic liquids by vapor deposition onto cobalt(II) oxide. Angew Chem Int Ed, 2017, 56: 90729076

29 Bauman Jr. JE, Wang JC. Imidazole complexes of nickel(II), copper(II), zinc(II), and silver(I). Inorg Chem, 1963, 3: 368-373

30 Liu J, Yu Y, Qi R, et al. Enhanced electron separation on in-plane benzene-ring doped g- $\mathrm{C}_{3} \mathrm{~N}_{4}$ nanosheets for visible light photocatalytic hydrogen evolution. Appl Catal B-Environ, 2019, 244: 459-464

31 Ravel B, Newville M. ATHENA, ARTEMIS, HEPHAESTUS: Data analysis for X-ray absorption spectroscopy using IFEFFIT. J Synchrotron Rad, 2005, 12: 537-541

32 Koningsberger DC, Prins R. X-Ray Absorption: Principles, Applications, Techniques of EXAFS, SEXAFS, and XANES. Vol. 92. New York: Wiley, 1988
33 Rehr JJ, Albers RC. Theoretical approaches to X-ray absorption fine structure. Rev Mod Phys, 2000, 72: 621-654

34 Li F, Han GF, Noh HJ, et al. Boosting oxygen reduction catalysis with abundant copper single atom active sites. Energy Environ Sci, 2018, 11: 2263-2269

35 Zhang $\mathrm{T}$, Zhang D, Han X, et al. Preassembly strategy to fabricate porous hollow carbonitride spheres inlaid with single $\mathrm{Cu}-\mathrm{N}_{3}$ sites for selective oxidation of benzene to phenol. J Am Chem Soc, 2018, 140: 16936-16940

36 Wang Y, Jia G, Cui X, et al. Coordination number regulation of molybdenum single-atom nanozyme peroxidase-like specificity. Chem, 2021, 7: 436-449

37 Pan Y, Chen $\mathrm{Y}, \mathrm{Wu} \mathrm{K}$, et al. Regulating the coordination structure of single-atom $\mathrm{Fe}-\mathrm{N}_{x} \mathrm{C}_{\mathrm{y}}$ catalytic sites for benzene oxidation. Nat Commun, 2019, 10: 4290

38 Li H, Cao C, Liu J, et al. Cobalt single atoms anchored on N-doped ultrathin carbon nanosheets for selective transfer hydrogenation of nitroarenes. Sci China Mater, 2019, 62: 1306-1314

39 Huang R, Cao C, Liu J, et al. Integration of metal single atoms on hierarchical porous nitrogen-doped carbon for highly efficient hydrogenation of large-sized molecules in the pharmaceutical industry. ACS Appl Mater Interfaces, 2020, 12: 17651-17658

40 Yang JH, Sun G, Gao Y, et al. Direct catalytic oxidation of benzene to phenol over metal-free graphene-based catalyst. Energy Environ Sci, 2013, 6: 793-798

41 Zhu Y, Sun W, Luo J, et al. A cocoon silk chemistry strategy to ultrathin $\mathrm{N}$-doped carbon nanosheet with metal single-site catalysts. Nat Commun, 2018, 9: 3861

42 Xiao X, Gao Y, Zhang L, et al. A promoted charge separation/transfer system from $\mathrm{Cu}$ single atoms and $\mathrm{C}_{3} \mathrm{~N}_{4}$ layers for efficient photocatalysis. Adv Mater, 2020, 32: 2003082

43 Zhang $\mathrm{T}, \mathrm{Nie} \mathrm{X}, \mathrm{Yu}$ W, et al. Single atomic $\mathrm{Cu}-\mathrm{N}_{2}$ catalytic sites for highly active and selective hydroxylation of benzene to phenol. iScience, 2019, 22: 97-108

44 Zhou H, Zhao Y, Gan J, et al. Cation-exchange induced precise regulation of single copper site triggers room-temperature oxidation of benzene. J Am Chem Soc, 2020, 142: 12643-12650

45 Deng D, Chen X, Yu L, et al. A single iron site confined in a graphene matrix for the catalytic oxidation of benzene at room temperature. Sci Adv, 2015, 1: e1500462

$46 \mathrm{Xu}$ J, Chen Y, Hong Y, et al. Direct catalytic hydroxylation of benzene to phenol catalyzed by vanadia supported on exfoliated graphitic carbon nitride. Appl Catal A-General, 2018, 549: 31-39

47 Zhang M, Wang YG, Chen W, et al. Metal (hydr)oxides@polymer core-shell strategy to metal single-atom materials. J Am Chem Soc, 2017, 139: 10976-10979

48 Wu K, Zhan F, Tu R, et al. Dopamine polymer derived isolated singleatom site metals/ $\mathrm{N}$-doped porous carbon for benzene oxidation. Chem Commun, 2020, 56: 8916-8919

Acknowledgements The authors acknowledge the financial support from the National Key R\&D Program of China (2018YFA0208504 and 2018YFA0703503), the National Natural Science Foundation of China (21932006) and the Youth Innovation Promotion Association of CAS (2017049).

Author contributions Shen Q performed the experiments; Zheng L performed the XAFS characterization and analysis; Cao $\mathrm{C}$ and Song $\mathrm{W}$ designed the experiments; Shen Q, Cao C and Song W co-wrote the paper. All authors contributed to the general discussion.

Conflict of interest The authors declare no conflict of interest.

Supplementary information Supporting data are available in the online version of the paper. 


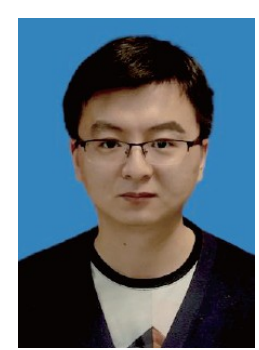

Qikai Shen received his BSc degree from Shandong University in 2016. Currently, he is a $\mathrm{PhD}$ student under the supervision of Prof. Weiguo Song at the Institute of Chemistry, Chinese Academy of Sciences. His research interests are focused on the design and fabrication of single-atom catalysts for heterogeneous hydrogenation and oxidation catalysis.

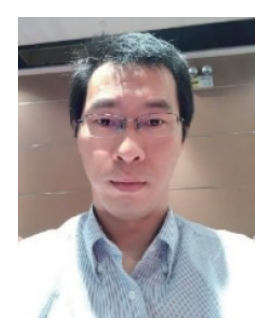

Lirong Zheng obtained his $\mathrm{PhD}$ from the Institute of High Energy Physics (IHEP), Chinese Academy of Sciences in 2011. Since then, he has been working at the XAFS beamline of Beijing Synchrotron Radiation Facility at IHEP. His research interest is focused on the XAFS theory, method, data analysis, and applications.

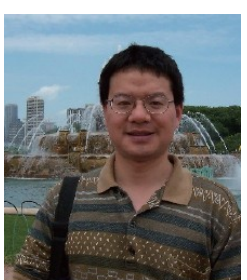

Weiguo Song obtained his Bachelor's degree from Peking University in 1992 and $\mathrm{PhD}$ from the University of Southern California in 2001. currently, he is a full professor at the Institute of Chemistry, Chinese Academy of Sciences. His current research interest mainly focuses on the synthesis of nanostructured materials and their applications in heavy metal-ion adsorption and nanocatalysis.

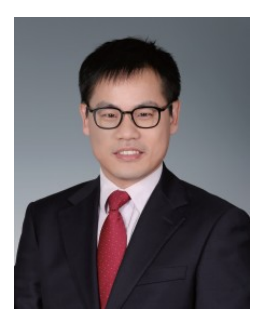

Changyan Cao obtained his PhD from Harbin Institute of Technology in 2011. Then, he worked as a postdoctor under the supervision of Prof. Weiguo Song at the Institute of Chemistry, Chinese Academy of Sciences. Currently, he is an associate professor in Prof. Weiguo Song's group. His research interest mainly focuses on the design and controllable synthesis of nanocatalysts and single-atom catalysts for thermal catalysis.

\section{离子液体辅助合成金属单原子催化剂用于苯氧化制} 苯酚

沈齐凯 ${ }^{1,2}$, 李佩佩 1,2 , 陈伟明 1,2 , 晋红强 1,2 , 于珈 ${ }^{1,2}$, 朱磊 1,2 , 杨者成 1,2 , 赵润卿 1,2 , 郑黎荣 $3^{*}$, 宋卫国 $1,2^{*}$, 曹昌燕 $1,2^{*}$

摘要 离子液体具有成本低、环境友好、杂原子丰富、溶解性好、与 金属离子良好的配位能力等优点, 是一种理想的用于制备金属单原子 催化剂的前驱体材料. 在本文中, 我们利用离子液体与金属的强配位能 力, 以 $\mathrm{g}-\mathrm{C}_{3} \mathrm{~N}_{4}$ 纳米片为结构模板, 合成了多种针定在氮掺杂超薄碳纳米 片上的金属单原子催化剂(分别简写为 $\mathrm{Cu}_{1} / \mathrm{NC} 、 \mathrm{Fe}_{1} / \mathrm{NC} 、 \mathrm{Co}_{1} / \mathrm{NC}$ 、 $\mathrm{Ni}_{1} / \mathrm{NC}$ 和 $\mathrm{Pd}_{1} / \mathrm{NC}$ ). 将上述金属单原子催化剂用于双氧水氧化苯制苯酚 反应中, $1000^{\circ} \mathrm{C}$ 煅烧得到的铜单原子催化剂 $\left(\mathrm{Cu}_{1} / \mathrm{NC}-1000\right)$ 表现出最高 的活性, $60^{\circ} \mathrm{C}$ 时反应 $1 \mathrm{~h}$ 的转换频率(TOF)约为 $200 \mathrm{~h}^{-1}$, 优于文献报道的 大多数金属单原子催化剂. 随着反应时间延长, 最终苯的转化率可达 $82 \%$, 苯酚的选择性维持在 $96 \%$. 此外, $\mathrm{Cu}_{1} / \mathrm{NC}-1000$ 催化剂具有良好的 循环稳定性. 本研究为制备单原子催化剂提供了一种新的有效的普适 性策略. 